\title{
Malignant otitis externa complicated by multiple cervical-petrous internal carotid artery pseudoaneurysms: a case report
}

\author{
James SK Lau ${ }^{1,2}$, BSc, MB, BS, Jane CY Wong ${ }^{1}$, MB, BS, Rebecca YT Ng ${ }^{1}$, FCSHK, FHKAM (Surgery), \\ Vincent KY Pang', FRCS, FHKAM (Surgery), CK Wong', FRCS, FHKAM (Surgery) \\ ${ }^{1}$ Department of Neurosurgery, Pamela Youde Nethersole Eastern Hospital, Chai Wan, Hong Kong \\ ${ }^{2}$ Accident and Emergency Department, Ruttonjee Hospital, Wan Chai, Hong Kong \\ * Corresponding author: janewongcy@gmail.com
}

Hong Kong Med J 2019;25:152-5

https://doi.org/10.12809/hkmj165016

\section{Case report}

Pseudoaneurysms that arise from malignant otitis externa (MOE) are a rare and potentially fatal condition. This is the first reported case of cervical-petrous internal carotid artery (ICA) pseudoaneurysm due to secondary MOE.

A 59-year-old man with poorly controlled diabetes mellitus and end-stage renal failure presented with a 1-week history of right ear hearing loss and tinnitus. Tympanic examination was normal and he was treated with intratympanic steroids. Three weeks later he was diagnosed with chronic suppurative otitis media and completed a course of oral ciprofloxacin and ototopic ofloxacin. Despite treatment, his condition deteriorated and he developed otitis externa that was complicated by a grade IV facial nerve palsy after 6 weeks. A pus swab from the ear grew Pseudomonas aeruginosa and biopsy of an aural polyp was compatible with infection. Computed tomography of the temporal bone excluded the presence of osteomyelitis. Over the following 3 months of out-patient consultations, he complained of intermittent otorrhea and was prescribed multiple courses of ciprofloxacin, the longest course lasting 3 weeks.

The patient developed fifth and twelfth cranial nerve palsies in addition to facial nerve palsy that persisted for 16 weeks. Computed tomography of the brain revealed lytic changes along the skull base (Fig $a$ and $b$ ) and he was diagnosed with grade II MOE. Six weeks of meropenem was commenced but he developed epistaxis and blood-stained otorrhea after 2 weeks. Computed tomography angiogram revealed multiple pseudoaneurysms at the right ICA situated between the subpetrous and proximal cavernous segments (Fig c). His blood pressure was stable throughout with no drop in haemoglobin. Balloon occlusion test (BOT) demonstrated sufficient crossshunting to the right anterior circulation via the anterior communicating artery as well as from the right external carotid artery even under hypotensive challenge. The patient remained neurologically stable throughout the test that lasted 40 minutes.
Trapping of the right ICA was then performed with coil embolisation of the cervical segment and the horizontal part of the cavernous segment separately (Fig $\mathrm{d}$ and $\mathrm{e}$ ), in order to minimise deposition of any foreign body at the infected region.

Postoperatively, he was stable and was discharged home with an 8-week course of ciprofloxacin and amoxillin clavulanate. Gallium scan was repeated at 3 and 8 weeks postoperatively and revealed further interval decrease in uptake over the right skull with mild residual gallium activity. His otalgia and fifth and twelfth cranial nerve palsy subsided subsequently. Three months after embolisation, he continues to suffer residual grade III 7th nerve palsy and otorrhea.

\section{Discussion}

Cervical-petrous internal carotid artery pseudoaneurysms can arise from different aetiologies including congenital, trauma, malignancy, radiation therapy, and infection. Cases of ruptured ICA pseudoaneurysm due to otogenic infection are rare with only four cases reported ${ }^{1-4}$; these cases were MOE complicated by pseudoaneurysm on only one ICA segment. This is the first reported case of pseudoaneurysm occurring on multiple segments of the ICA with rupture due to MOE, and demonstrates the features that predict development of complex vascular complications of unresolved otogenic infection, the timing of appropriate imaging modalities, and appropriate algorithm and duration of treatments to prevent or rescue a fatal carotid blowout.

Malignant otitis externa is becoming an increasingly common condition as a consequence of the prevalence of diabetes and other immunocompromised states. It is an aggressive infection that involves the external ear canal, either primarily originating from the external auditory canal or secondary to chronic suppurative otitis media. Pseudomonas aeruginosa is the most common causative organism. ${ }^{1}$ Conventionally, MOE is classified according to the structural involvement 


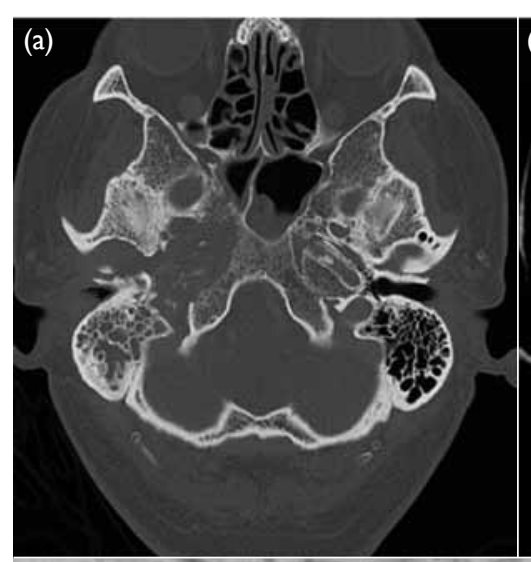

(d)
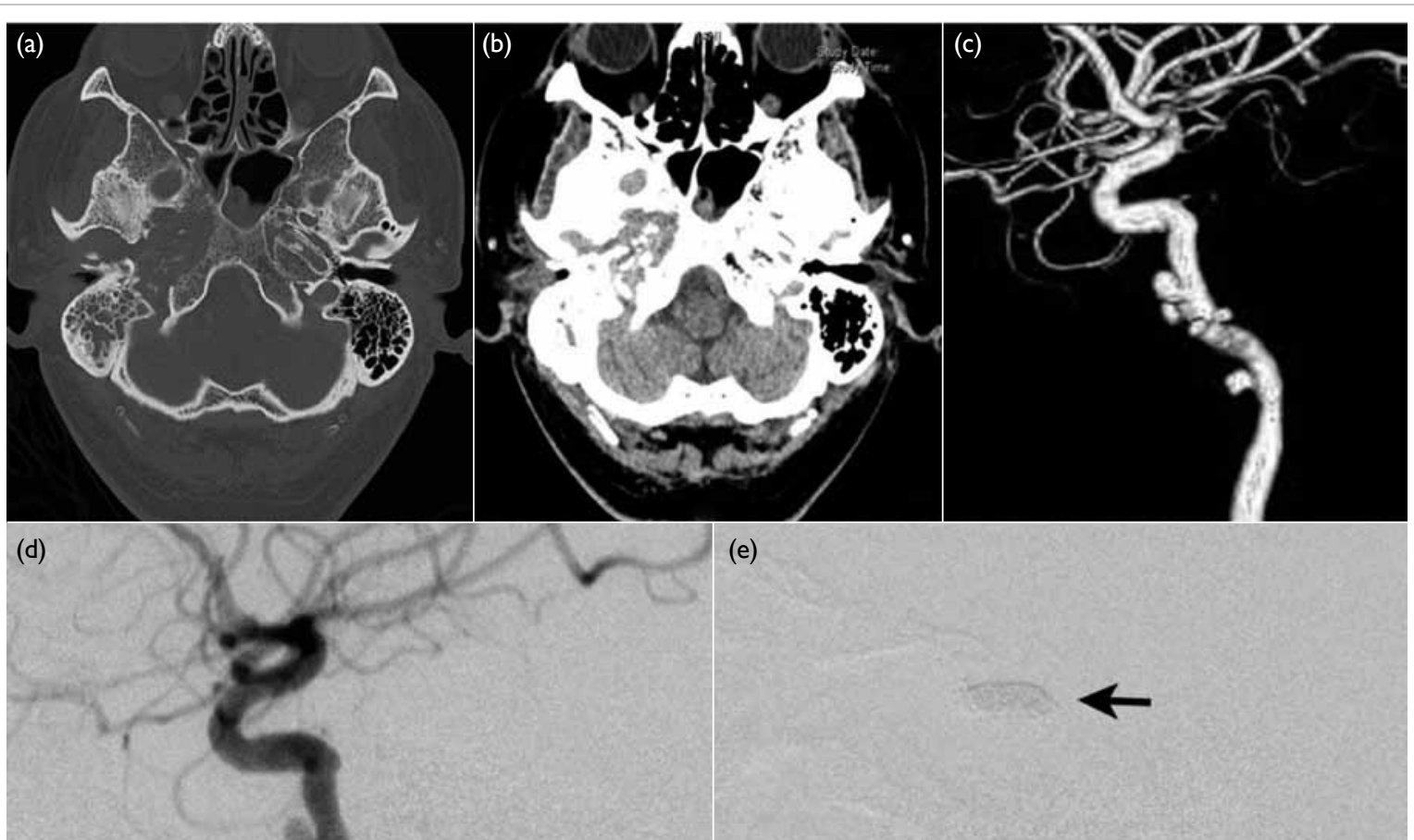

(e)

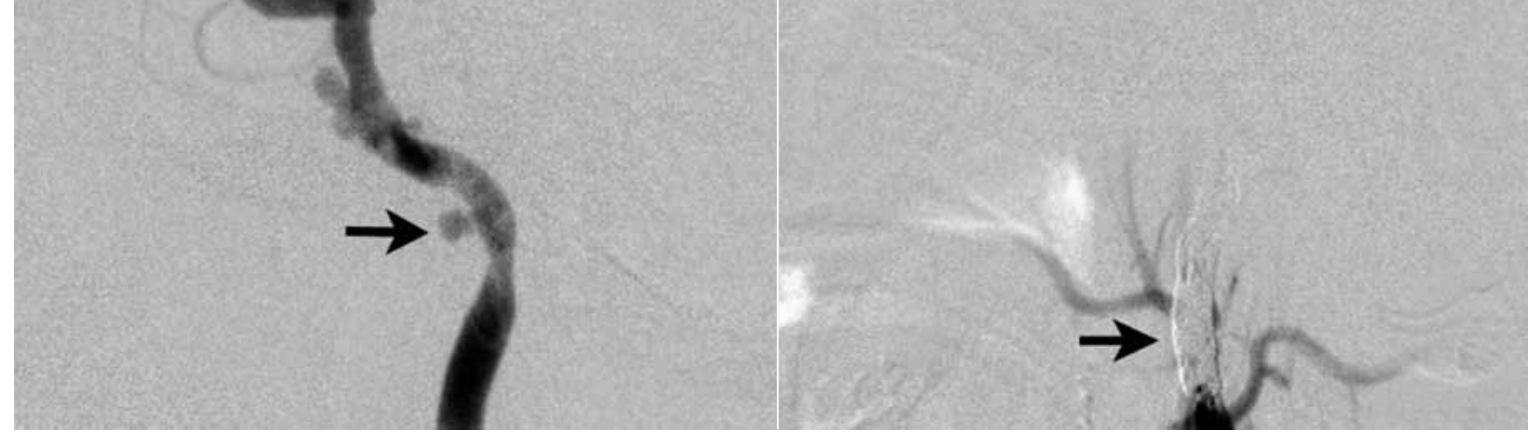

FIG. (a) Plain computed tomography brain (axial, bone window) showing extensive bony erosion over right temporomandibular joint, sphenoid, petrous apex, and clivus. (b) Brain window of Figure a. (c) Three-dimensional reconstruction of DSA showing multiple pseudoaneurysms at subpetrous and subcavernous segments of the right ICA. (d) Lateral view of the right ICA DSA showing multiple pseudoaneurysms. The subpetrous one (arrow) measuring $4.67 \mathrm{~mm} \times 3.76 \mathrm{~mm}$ is believed to be the source of the haemorrhage. A few more were at the subcavernous segment. (e) Control injection of right ICA after trapping showing no forward flow to distal ICA but reflux to right external carotid artery. The infected ICA segment was trapped by two Ruby Coils (Penumbra,Alameda [CA], US) and an Interlock-18 Fibered IDC Occlusion System (Boston Scientific Corporation, Malborough [MA], US) proximally, and three Target Detachable Coils (Stryker, Kalamazoo [MI], US) distally (arrows)

Abbreviations: $\mathrm{DSA}=$ digital subtraction angiogram; ICA = internal carotid artery

(Table). ${ }^{5}$ In stage II MOE, complications can arise as it invades the temporal bone and surrounding nerve and vascular structures causing multiple cranial nerve palsies and carotid pseudoaneurysms. Ruptured mycotic pseudoaneurysm has an alarming mortality rate of $54 \%$ due to shock, aspiration and ultimately cardiopulmonary arrest. ${ }^{4}$ Furthermore, cavernous sinus thrombosis and cerebral venous sinus thrombosis can occur when the internal jugular vein is affected.

In our patient, the time to diagnosis of MOE was 12 weeks compared with an average of 13 weeks. ${ }^{1}$ Because the possible mechanisms of the palsies include contiguous infectious spread or direct compression by the pseudoaneurysm, it is paramount that we recognise the warning signs of pseudoaneurysm and instigate appropriate investigations and treatment (Table).

\section{Treatment of malignant otitis externa and its complications}

A prolonged course of culture-directed antibiotics remains the mainstay treatment for osteomyelitis, especially when surgical debridement at the skull base is not feasible. Because Pseudomonas aeruginosa is the most common bacterial organism in MOE, an antipseudomonal antibiotic such as ceftazidime is preferred. With regard to duration, 4 to 6 weeks is optimal with the rationale that bone revascularisation takes 3 to 4 weeks. Gallium-67 
TABLE. Stages, clinical features, and management of malignant otitis externa

\begin{tabular}{|c|c|c|c|c|}
\hline Stage & Area of involvement & Symptom/sign & Investigation & Treatment \\
\hline I & $\begin{array}{l}\text { EAC and adjacent soft } \\
\text { tissue and/or facial nerve }\end{array}$ & $\begin{array}{l}\text { Facial paralysis, hearing deficit, } \\
\text { disproportional otalgia, purulent } \\
\text { otorrhea, trismus, vertigo and } \\
\text { tinnitus, headache }\end{array}$ & $\begin{array}{l}\text { - Otoscope to look for granulation } \\
\text { tissue } \\
\text { - Pus swab } \\
\text { - Biopsy }\end{array}$ & $\begin{array}{l}\text { - Antipseudomonal antibiotics } \\
\text { (both systemic and ototopic) for } \\
\text { 4-6 weeks } \\
\text { - Local debridement }\end{array}$ \\
\hline II & $\begin{array}{l}\text { Stage I and (skull base and/ } \\
\text { or multiple cranial nerves) }\end{array}$ & $\begin{array}{l}\text { - Warning signs } \\
\text { - Pseudoaneurysms: bulbar } \\
\text { palsies, otorrhagia and epistaxis } \\
\text { Thrombophlebitis of IJV that can } \\
\text { cause sinus thrombosis: neck } \\
\text { swelling, Lemierre's syndrome, } \\
\text { blurred vision, papilloedema, } \\
\text { headache, seizure, altered } \\
\text { mental status } \\
\text { - Cranial nerves V, IX, X, XI and XII } \\
\text { palsies }\end{array}$ & $\begin{array}{l}\text { - } \text { CT temporal bone and brain } \\
\text { - MRI brain/neck } \\
\text { - CT/MR arteriogram/venogram of } \\
\text { head/neck } \\
\text { - Gallium- } 67 \text { scan } \\
\text { - Digital subtraction angiography } \\
\text { of head/neck }\end{array}$ & $\begin{array}{l}\text { - Extended duration of antibiotic } \\
\text { treatment according to gallium } \\
\text { scans, subsequent positive } \\
\text { cultures, clinical picture } \\
\text { - Adjuvant hyperbaric oxygen } \\
\text { therapy } \\
\text { - Treatment of complications }\end{array}$ \\
\hline III & $\begin{array}{l}\text { Stage II and intracranial } \\
\text { infections }\end{array}$ & Meningism, signs of increased ICP & $\mathrm{CT} / \mathrm{MRI}$ brain with contrast & $\begin{array}{l}\text { - Antibiotics } \\
\text { - Adjuvant hyperbaric oxygen } \\
\text { therapy } \\
\text { - Drainage of abscesses }\end{array}$ \\
\hline
\end{tabular}

Abbreviations: CT = computed tomography; EAC = external auditory canal; ICP = intracranial pressure; IJV = internal jugular vein; MRI = magnetic resonance imaging

citrate scintigraphy and indium scintigraphy scans are sensitive to active infection and can be used to monitor treatment progress, guide duration of antibiotic administration, and prevent recurrence.

Other than antibiotics and local debridement and drainage of abscesses, adjuvant hyperbaric oxygen therapy has been reported to improve the clinical course of MOE. Despite the absence of randomised controlled trials, adjuvant hyperbaric oxygen therapy has been shown since the 1980s to be effective in numerous patients. It should be strongly considered in stage II $\mathrm{MOE}^{5}$ to minimise intracranial involvement that brings high mortality. Hyperbaric oxygen therapy is postulated to enhance phagocytic action via free radicals, minimise tissue hypoxia that otherwise leads to further infection and augment antibiotic activity.

An endovascular approach is frequently adopted in the treatment of ICA pseudoaneurysm since expertise and accessibility in open surgery are limited. ${ }^{6}$ Depending on the anatomy of the aneurysm, collateral flow sufficiency and the segment involved, either a reparative or destructive approach is used. ${ }^{6}$ In a life-threatening scenario, we prefer a more aggressive approach of occluding the parent artery/trapping as it protects both the aneurysm and the frequently diseased ICA segment. A BOT can identify those who cannot tolerate permanent carotid occlusion that has a complication rate of $1.6 \%$ for neurological deficits. ${ }^{7}$ Alternatively, a failure rate of $4.7 \%$ and permanent stroke can occur after passing BOT. ${ }^{7}$ For patients who fail BOT, a reparative approach such as stenting or stent-assisted coiling may be considered but there is a risk of further infection due to foreign body deposition around the infected segment. In this case, we avoided such infection by not implanting coils in the diseased ICA segment. Coils were instead deployed at segments of the ICA both proximal (cervical) and distal (cavernous) to the diseased segment as illustrated in Figure e. Definitively, performing a high-flow bypass prior to surgical ligation of the parent artery can avoid the issues mentioned.

The patient in this case had multiple risk factors including longstanding uncontrolled diabetes mellitus and end-stage renal failure. In retrospect, the use of intratympanic steroids along with intermittent antibiotics could have further worsened his clinical course. With progression of symptoms despite antibiotics, we should have had a high clinical suspicion of MOE and treated appropriately before complications developed. In the presence of multiple cranial nerve palsies or even facial nerve palsy alone, timely vascular imaging is crucial to exclude the presence of pseudoaneurysms.

In conclusion, this case highlights the rare but important complication of MOE and the warning symptoms associated with pseudoaneurysms. Early involvement of ear, nose, and throat specialists and neurosurgeons can expedite the time to diagnosis and allow for prompt investigations and intervention.

\section{Author contributions}

All authors had full access to the data, contributed to the study, approved the final version for publication, and take responsibility for its accuracy and integrity. 
Concept or design: All authors.

Acquisition of data: JSK Lau, JCY Wong, RYT Ng.

Analysis or interpretation of data: All authors.

Drafting of the manuscript: JSK Lau, JCY Wong, RYT Ng.

Critical revision for important intellectual content: All authors.

\section{Conflicts of interest}

All authors have disclosed no conflicts of interest.

\section{Funding/support}

This research received no specific grant from any funding agency in the public, commercial, or not-for-profit sectors.

\section{Ethics approval}

The patient was treated in accordance with the Declaration of Helsinki. The patient provided informed consent for all procedures.

\section{References}

1. Baker A, Rizk H, Carroll W, Lambert P. Cervical internal carotid artery pseudoaneurysm complicating malignant otitis externa: first case report. Laryngoscope 2015;125:733-5.

2. Oyama H, Hattori K, Tanahashi S, Kito A, Maki H, Tanahashi K. Ruptured pseudoaneurysm of the petrous internal carotid artery caused by chronic otitis media. Neurol Med Chir (Tokyo) 2010;50:578-80.

3. Telmesani LM. Ruptured petrous carotid pseudoaneurysm complicating malignant otitis externa. J Otolaryngol 2004;33:278-80.

4. Yagci AB, Ardiç FN, Oran I, Bir F, Karabulut N. Ruptured petrous carotid pseudoaneurysm due to tuberculous otitis: endovascular treatment. Interv Neuroradiol 2006;12:53-6.

5. Davis JC, Gates GA, Lerner C, Davis MG Jr, Mader JT, Dinesman A. Adjuvant hyperbaric oxygen in malignant external otitis. Arch Otolaryngol Head Neck Surg 1992;118:89-93.

6. Powitzky R, Vasan N, Krempl G, Medina J. Carotid blowout in patients with head and neck cancer. Ann Otol Rhinol Laryngol 2010;119:476-84.

7. Mathis JM, Barr JD, Jungreis CA, et al. Temporary balloon test occlusion of the internal carotid artery: experience in 500 cases. AJNR Am J Neuroradiol 1995:16:749-54. 